Many doctors used to feel that the greatest of our professional hazards was the mistake that kills. Has it now been usurped by that which keeps the patient alive ?-I am, etc., Walton-on-Thames,
Surrey.

MEYRICK EMRYS-ROBERTS.

\title{
Surgical Treatment of Peptic Ulcer
}

SIR,-The article by Mr. J. L. Dawson (11 October, p. 102) on the present position about the operative treatment of peptic ulcer is concise and comprehensive, and raises points of considerable interest.

The criticism of the performance of vagotomy and pyloroplasty rather than resection in the case of gastric ulcer-and thereby running the risk of missing an early carcinoma-is one such point. However, it is not only malignancy in the obvious gastric ulcer which is in danger of being missed. There are a number of patients in which

\section{Testing for Phenylketonuria}

SIR,-While accepting the criticisms levelled at your news paragraph headed "Testing for Phenylketonuria" by Dr. J. A. J. Macleod (11 October, p. 112), I trust that his comments will not deter the people who may wish to introduce a more certain programme for the detection of phenylketonuria.

I commend to Dr. Macleod our report of experience in the South-Eastern Scotland Hospital Region, ${ }^{1}$ comprehensive coverage of which by the Guthrie test operated from Stevenson's laboratory in Stobhill, Glasgow, provided the basis for further studies and recommendations. These are very flexible in that specimens can be taken anywhere by an appropriate person at any time from the sixth day, but preferably before the fourteenth. We reserve the right to change at any time to any other fully tested method which enjoys the same advantage as the Guthrie test. Any nationally recommended method must be as easily applied in a shepherd's remote mountain cottage 100 miles $(160 \mathrm{~km}$.) from a laboratory, but relatively near a mailbox, as in the population clustered tightly around Lewisham. Dr. Macleod will no doubt appreciate the possible difficulty in mailing a capillary tube of plasma to Glasgow from a Hebridean croft. We also acknowledge the advantages in chromatography or in a dua programme of bacteriological and biochemical screening, but for the above reason we see difficulties in the mailing of capillary specimens although there are methods for assuring safe transport used, we believe, by some of our colleagues in Scotland.

H.M.(69)72 does not, of course, apply to Scotland but English administrators are no doubt well aware of it and may already have drawn to it the attention of all concerned with putting it into practice. I think the document is at least a very fair one which makes provision for the continued use of other established methods and probably for the trial of new ones. In a day when there are doctors who on grounds of expense are yet unconvinced of the justification for screening all, rather than "at risk," newborn infants the cost of each test from the taking of blood to the mailing of final results to surgery is performed for "proved" duodenal ulcer, where, on opening up the specimen after performing a partial gastrectomy, a second peptic ulcer is found in the stomach. One cannot depend on negative findings at the time of the laparotomy, as there may be no external signs whatsoever of the presence of an ulcer in the stomach. Nor can one depend on negative $x$-ray findings.

The performance of a four-quadrant biopsy of the ulcer and frozen section examination is indeed essential at the time of operation if the ulcer is not to be resected, but this only safeguards the patient with the gastric ulcer which happens to be obvious at laparotomy. Inspection of the gastric mucosa can be carried out through a gastrotomy incision, but this, combined with the taking of a biopsy of the ulcer, adds to the length and severity of the operation, and tends to destroy one of the attractions of "vagotomy and pyloroplasty" - that of being a lesser procedure.-I am, etc.,

London W.1.

Norman Pitt.

the doctors concerned will appeal to every Scot from the Farquhars of Invercauld to the Macleods of the Outer Hebrides, and certainly to administrators of any nationality.

These comments are, of course, personal ones, and are not those of the working party on phenylketonuria whose report (5 October 1968 , p. 7) has provoked this correspondence. -I am, etc.

\section{Department of Child Life University of Edinburgh. REFERENCE \\ Consultant Paediatricians and Medical Officers of Health of the S.E. Scotland Hospital Region, British Medical fournal, 1968, 1, 674.}

SIR,-Dr. J. A. J. Macleod's letter (11 October, p. 112) implies that as a screening test for phenylketonuria the Guthrie test is inferior to the Scriver test, and is already being replaced by it in some areas. Before reaching any conclusions your readers might wish to consider the following points :

(1) It is generally agreed that of the inborn errors of metabolism only phenylketonuria satisfies criteria for mass screening, at least at the present. Suitability for detecting phenylketonuria must therefore be the decisive consideration in selecting a test.

(2) The Guthrie test appears superior for this purpose to the Scriver test because it is semiquantitative, because collection and transport specimens are easier, and because samples are less likely to deteriorate in transit.

(3) The fact that the Scriver test will detect a proportion of other inborn errors of metabolism is extremely useful to those looking for examples of these conditions or in research, but this is not relevant here. Indeed, if we wer mass screening for, say, homocystinuria, histidinaemia, or hyperprolinaemia, the Scriver test would not be suitable because it does not pick up a sufficiently large proportion of these cases

(4) If, as is conceivable, the time comes to replace the Guthrie test, the choice is unlikely to fall on the Scriver test, which is not readily adaptable to automation and depends on personal interpretation of the chromatograms. The decision of what is normal or abnormal is therefore of necessity arbitrary, and, for example, if all cases of mildly raised tyrosine levels were followed up the retest rate might be as high as $10 \% .^{1}$
The Scriver test is used routinely in our hospital and we find it a most valuable test in the laboratory, but not for mass screening for phenylketonuria.-We are, etc.,

R. L. Newman. J. STERN.

Queen Mary's Hospital for Children, Carshalton, Surrey.

REPERENCE

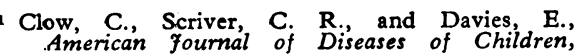
American foum, 48.

\section{The Consultant's Job}

SiR,-The first fallacy in the document The Responsibilities of the Consultant Grade is that men will progress evenly to consultant posts in eight years after qualification. Many will not achieve the required level in eight years, or ever. Places for these people should be found in their specialty, if they so wish, below consultant level. They will not be happy at having failed to reach their goal, but such is life.

The second fallacy is to be found in the proposition that after eight years' training a man will spend 33 years as a consultantappointed at 32 , retiring at 65 . There would be four times as many consultants as trainees. The complexities of modern medicine and surgery demand teamwork, and a team must have a captain and a chain of command. How are the hospitals to be covered by "resident" staff? How are operating lists and outpatient sessions to be organized? How are consultants to obtain enough experience to be worth consulting ?

These reflections are sufficient to show that the proposals in the report are entirely impracticable, and one wonders why authors should have put their names to it. It is possible, as Dr. G. F. M. Pierce and his colleagues (9 August, p. 362) say, that many of them have a severely limited knowledge of regional consultant responsibility ; or that they share the belief of modern planners that there is something magical about the present time which allows the accumulated experience of generations (as a result of which the present world-wide hospital hierarchy system has built up) to be cast away.

The really fundamental error in the report from which all others have stemmed is to be found in paragraph 6 (i). The Spens Committee was not concerned, as this paragraph implies, with postgraduate training programmes but with remuneration. The Spens Committee assumed on very scant evidence, that men were appointed to consultant posts at 32 , and recommended salary scales which in their view were appropriate for men of this age and experience. In practice, as the report shows in paragraph 17, they are not appointed until 37 or 38 . This has meant that most of those in hospital service since it began, who have held or hold seniorregistrar or consultant posts, have always been held stationary for five to six years, both in progress and pay. Recent awards of the Kindersley Review Body have made a belated attempt to correct this by raising the top level of the senior-registrar scale, but these awards have done nothing to correct past injustice. The numbers of men in training, the lack of consultant posts, and the obsession with the "Spens age 32," has led to a gap between the senior registrar and the consultant and the report is an attempt to close it. It is impracticable to try to close it by turning all the registrars into consultants and all the consultants into registrars. 